ORIENTAL JOURNAL OF CHEMISTRY

An International Open Free Access, Peer Reviewed Research Journal

www.orientjchem.org
ISSN: 0970-020 X

CODEN: OJCHEG

2014, Vol. 30, No. (4):

Pg. 1815-1822

\title{
Development and Validation of RP - HPLC Method for the Simultaneous Determination Of Hydrochlorothiazide, Amlodipine Besylate and Telmisartan in Bulk and Pharmaceutical Formulation
}

\author{
RLC SASIDHAR $^{1 *}$, S.VIDYADHARA ${ }^{1}$, B.DEEPTI ${ }^{2}$, K.TEJASWI $^{1}$ and J.SUHASINI ${ }^{1}$ \\ ${ }^{1}$ Chebrolu Hanumaiah Institute of Pharmaceutical Sciences, Chowdavaram, Guntur - 19, India. \\ Vignan Pharmacy College, Vadlamudi, Guntur, India. \\ *Corresponding author E-mail: rlcsasidhar@gmail.com \\ http://dx.doi.org/10.13005/ojc/300442
}

(Received: August 06, 2014; Accepted: September 09, 2014)

\begin{abstract}
A reverse phase high performance liquid chromatographic method has been developed for the simultaneous estimation of Hydrochlorothiazide, Amlodipine Besylate and Telmisartan in pharmaceutical formulation using RP - C18 column. The mobile phase (acetonitrile: acetate buffer adjusted to $\mathrm{pH} 5$ with orthophosphoric acid) was pumped at a flow rate of $1.0 \mathrm{~mL} \mathrm{~min}^{-1}$ in the ratio of $60: 40 \% \mathrm{~V} / \mathrm{v}$ and the eluents were monitored at $333 \mathrm{~nm}$. Linearity was obtained in the concentration range of $20-100 \mu \mathrm{g} \mathrm{mL}^{-1}$ for hydrochlorothiazide, amlodipine besylate and telmisartan. The method was statistically validated and RSD was found to be less than $2 \%$ indicating high degree of accuracy and precision of the proposed HPLC method. Due to its simplicity, rapidness, high precision and accuracy, the proposed HPLC method can be applied for determining hydrochlorothiazide, amlodipine besylate and telmisartan in bulk and in pharmaceutical dosage form.
\end{abstract}

Key words: Hydrochlorothiazide, Amlodipine besylate and Telmisartan, RP - HPLC.

\section{INTRODUCTION}

Hydrochlorothiazide (Figure 1) (HCT), 6 chloro - 3, 4 - dihydro - 7 - sulfamoyl - 2H - 1, 2, 4 benzothia - diazine - 1, 1 - dioxide, is a thiazide diuretic ${ }^{1}$. It increases sodium and chloride excretion in distilled convoluted tubule. Many analytical methods for HCT alone or in combination with other drugs including spectroscopic and chromatographic methods are also reported in literature ${ }^{2-6}$.

Amlodipine besylate (Figure 2) (AMB), 2 [(2 - amino ethoxy) - methyl $]$ - 4 - (2 - chloro phenyl) -1, 4 -dihydro - 6 - methyl - 3, 5 - pyridine dicarboxylic acid 3 - ethyl - 5 - methyl ester, benzene sulfonate, is a potent dihydro calcium channel blocker ${ }^{1}$. Various analytical methods have been 
reported for the assay of $A M B$ alone or in combination with other anti - hypertensive agents in pharmaceutical formulations. They include UV spectroscopy, high performance liquid chromatography, high performance thin layer chromatography, , LC - MS and LC - MS/ MS ${ }^{7-13}$.

Telmisartan (Figure 3) (TEL),2-(4-\{[4methyl-6-(1-methyl-1H-1,3-benzodiazol -2-yl)-2propyl-1H-1, 3-benzodiazoll-1-yl] methyl\} phenyl) benzoic acid, is a angiotensin converting enzyme inhibitor and angiotensin - II type I receptor blocker. Various analytical methods have been reported for the assay of TEL alone or in combination with other agenst. They include UV spectroscopy, high performance liquid chromatography. All three drugs are official in $\mathrm{IP}^{14}, \mathrm{AMB}$ and $\mathrm{HCT}$ are official in $\mathrm{BP}^{15}$, HCT is official in USP. Literature survey revealed that there are several methods were reported for the estimation of HCT, AMB and TEL individually as well as in combination with some other drugs. As no method is reported for SIMULTAneous estimation of the three drugs HCT, AMB and TEL in combination, the present was aim to develop accurate, precise and sensitive HPLC method for estimation of HCT, AMB and TEL in bulk and combined tablet dosage form. For the analysis of marketed tablet, TELVAS*-3D containing $12.5 \mathrm{mg}$ of $\mathrm{HCT}, 5 \mathrm{mg}$ of $\mathrm{AMB}$ and $40 \mathrm{mg}$ of TEL was used ${ }^{16-19}$.

\section{EXPERIMENTAL}

\section{Instrumentation}

Analysis was performed with a Agilent ODS UG 5 column, $250 \mathrm{~mm} \times 4.5 \mathrm{~mm}$ with $\mathrm{C}_{18}$ column of injection capacity of $20 \mu \mathrm{L}$. The mobile phase was a $60: 40 \%(V / v)$ mixture of Acetonitrile: Acetate Buffer $(50 \mathrm{mM}, \mathrm{pH} 5 \pm 0.1$, adjusted with orthophosphoric acid). The flow rate was $1.0 \mathrm{~mL}$ $\mathrm{min}^{-1}$ and the run time was $15 \mathrm{~min}$. Before analysis both the mobile phase and sample solutions were degassed by the use of a sonicator (1.5LH Ultrasonic bath sonicator) and filtered through a $0.45 \mu$ membrane filter paper. The identity of the compounds was established by comparing the retention times of compounds in the sample solution with those in standard solutions. Chromatography was performed in an ambient temperature maintained at $20 \pm 1^{\circ} \mathrm{C}$. The UV spectrum of $\mathrm{HCT}$, $A M B$ and TEL for selecting the working wavelength of detection was taken using a LAB INDIA double beam UV - Visible spectrophotometer with pair of $10 \mathrm{~mm}$ matched quartz cells.

\section{Reagent and chemicals}

Pharmaceutically pure sample of HCT, AMB and TEL were obtained as a gift samples from Mylan laboratories. All solvents were of AR grade obtained from S.D. Fine chem. Limited, Mumbai. A combination of HCT(12.5 mg), AMB (5 mg), and TEL $(40 \mathrm{mg})$ in tablet formulation was procured from Indian market TELVAS*-3D, Aristo pharmaceutical Pvt. Ltd, India.

\section{Preparation of Stock Solution of HCT, AMB and} TEL

About 50mg of HCT, AMB and TEL were accurately weighed and transferred in to $50 \mathrm{~mL}$ volumetric flasks separately. It was dissolved in methanol and the solution was made up to the volume with same.

\section{Construction of Calibration Plots}

Calibration standards for each analyte were prepared at the concentrations of 20,40,60, 80 and $100 \mu \mathrm{g} \mathrm{mL}^{-1}$ for HCT, AMB and TEL. All the solutions were chromatographed and the peak areas were measured. Peak areas were that plotted against their respective concentrations for HCT, $A M B$ and TEL. From the plots it was found that all the drugs were linear in the concentration range of 20, 40, 60, 80 and 100 $\mathrm{g} \mathrm{mL}^{-1}$ for HCT, AMB and TEL rspectively. Unknown assay samples were quantified by reference to these calibration plots.

\section{Assay of tablet formulation}

The contents of twenty commercial tablets were weighed and their mean mass was determined. After grinding the tablets into a fine powder in a glass mortar, an accurately weighed quantity of the tablet powder equivalent to $40 \mathrm{mg}$ of TEL was quantitatively transferred into a $50 \mathrm{ml}$ volumetric flask with about $45 \mathrm{ml}$ of methanol. The contents were sonicated for $15 \mathrm{~min}$, to ensure the complete solubility of the drug. The mixture was then made up to $50 \mathrm{~mL}$ with methanol. The solution was made up to the mark with the solvent and filtered through a $0.45 \mu$ membrane filter paper. From the clear solution, further dilutions were made by diluting $1.0 \mathrm{~mL}$ into $10 \mathrm{~mL}$ with mobile phase; to 
obtain $100 \mu \mathrm{g} \mathrm{mL}^{-1}$ of TEL which is also contains $31.25 \mu \mathrm{g} \mathrm{mL}^{-1}$ of HCT and $12.5 \mu \mathrm{g} \mathrm{mL}^{-1}$ of AMB theoretically. Each sample solution was injected and the peak areas were measured for the determination of HCT, AMB and TEL in tablet formulation.

\section{Statistical Calculations}

Standard regression curve analysis was performed by use of Microsoft Office Excel 2007 software (Microsoft, USA), without forcing through zero. Means, standard deviations and other statistical parameters were calculated by use of SPSS software version 9.5 (SPSS, Cary, NC, USA).

\section{Validation}

The objective of method validation is to demonstrate that the method is suitable for its intended purpose as it is stated in $\mathrm{ICH}$ guidelines. The method was validated for linearity, precision (repeatability and intermediate precision), accuracy, selectivity and specificity. Accuracy was assessed by measuring recovery at three different levels. Precision assessed by measurement of intra and inter day precision. In the intraday study the concentrations of all the drugs were calculated six times on the same day at different time intervals. In the inter day study the concentrations of the drugs were calculated on six different days. Selectivity and specificity of the method were assessed by injecting solutions containing all the drugs; after chromatography three sharp peaks were obtained for all drugs. LOD and LOQ were measured to evaluate the detection and quantitation limits of the method and to determine whether these were affected by the presence of impurities. They were calculated by use of the equations LOD $=3.3 \mathrm{\sigma} / \mathrm{S}$ and $L O Q=10 \sigma / S$, where $\sigma$ is the standard deviation of the response and $S$ is the slope of the calibration plot ${ }^{19-20}$

\section{Stability Studies}

To determine whether the developed method was stability indicating the tablets were stressed under different conditions to promote degradation. Regulatory guidance in $\mathrm{ICH}$ Q2A, Q2B, Q3B and FDA 21 CFR section 211 requires the development and validation of stabilityindicating potency assays ${ }^{21}$. The tablet formulation was exposed to dry heat in oven at $70^{\circ} \mathrm{C}$ about 48h. The tablets were then removed from the oven and were powdered. The solutions of the sample were prepared in mobile phase and injected to chromatographic system.

\section{RESULTS AND DISCUSSION}

\section{HPLC Method Development and Optimization}

The multi component formulations have gained a lot of importance as there is greater patient acceptability, increased potency and decreased side effects. HCT, AMB and TEL are a recent combination in the market used for the treatment of hypertension. This work was focused on optimization of the conditions for the simple and rapid as well as low cost effective analysis including a selection of the proper column or mobile phase to obtain satisfactory results.

Solvent type, solvent strength (volume fraction of organic solvent(s) in the mobile phase and $\mathrm{pH}$ of the buffer solution), detection wavelength, and flow rate were varied to determine the chromatographic conditions giving the best separation. The mobile phase conditions were optimized so there was no interference from solvent and excipients.

\section{Method development was started with Acetonitrile}

Phosphate buffer pH-3.6 (55:45), but only two drugs were eluted, TEL was not eluted up to 10 min. The mobile phase was changed to Acetonitrile:Phosphate Buffer with pH-3.0 (50:50),

Table 1: Results from system suitability study

\begin{tabular}{lccc}
\hline Parameters & HCT* & AMB* & TEL* \\
\hline Retention time & 2.56 & 3.80 & 7.10 \\
Tailing Factor & 1.42 & 1.35 & 1.34 \\
Asymmetrical Factor & 1.78 & 1.56 & 1.52 \\
Number of & & & \\
Theoritical plates & 2725 & 4598 & 6233 \\
Capacity factor & 1.58 & 2.38 & 4.24 \\
Resolution & Between & Between & \\
& HCT and & AMB & \\
& AMB 1.24 & and TEL 3.3 \\
\hline
\end{tabular}

*Mean of six determinations. 
but resolution is less. The mobile phase was changed to Acetonitrile:Acetate Buffer pH-5.0 (50:50), but resolution is less. The mobile phase was then adjusted by mixing acetonitrile with Acetate buffer $(50 \mathrm{mM})$ in the ratio $60: 40 \% \mathrm{~V} / \mathrm{v}$. This resulted in distorted signals that were not well defined. Addition of $0.4 \mathrm{~mL}$ orthophosphoric acid and subsequent adjustment of the $\mathrm{pH}$ of buffer resulted in good separation and symmetrical peaks. To determine the appropriate wavelength for simultaneous determination of $\mathrm{HCT}, \mathrm{AMB}$ and TEL, solutions of these compounds in mobile phase were scanned in the range of $200-400 \mathrm{~nm}$. From the overlaid UV spectra, suitable wavelength choices considered for monitoring the drugs at $333 \mathrm{~nm}$ (Figure 2). Solutions of each substance in the mobile phase were also injected directly for HPLC analysis and the responses (peak area) were recorded at $333 \mathrm{~nm}$. It was observed that all analytes absorbed well at $333 \mathrm{~nm}$, and at this wavelength there was no interference from the mobile phase or baseline disturbance, and it was, therefore, concluded that $333 \mathrm{~nm}$ was the most appropriate wavelength for analysis of all the drugs with suitable sensitivity.

The optimum mobile phase was, therefore, Acetonitrile: Acetate Buffer in the ratio of 60:40 (v/ v). Under these experimental conditions sharp

Table 2: Results from study of linearity

\begin{tabular}{lccc}
\hline Parameters & HCT* & AMB* & TEL $^{*}$ \\
\hline Detection wavelength & & $333 n m$ & $20-100$ \\
Beer's law limit $\left(\mu \mathrm{g} \mathrm{mL}^{-1}\right)$ & $20-100$ & $20-100$ & 0.999 \\
Correlation & 0.999 & 0.999 & \\
Coefficient $(\mathrm{r})$ & & & $\mathrm{Y}=11079 \times-25536$ \\
Regression equation $(\mathrm{y}=\mathrm{mx}+\mathrm{C})$ & $\mathrm{Y}=14245 \mathrm{x}+40813$ & $\mathrm{Y}=10121 \mathrm{x}+15999$ & 11079 \\
Slope & 14245 & 10121 & 25536 \\
Intercept $(\mathrm{a})$ & 40813 & 15999 & 7.60 \\
LOD $(\mu \mathrm{g} \mathrm{mL}-1)$ & 5.2 & 9.45 & 25.08 \\
LOQ $\left(\mu \mathrm{g} \mathrm{mL} \mathrm{mL}^{-1}\right)$ & 17.16 & 31.18 & \\
\hline
\end{tabular}

*Mean of six determinations.

Table 3: Results from assay of tablet formulation

\begin{tabular}{|c|c|c|c|c|c|c|c|c|}
\hline \multicolumn{3}{|c|}{ Amount Present in (mg/tab) } & \multicolumn{3}{|c|}{ Amount Obtained in(mg/tab) } & \multicolumn{3}{|c|}{ Label Claim \%w/w } \\
\hline $\mathrm{HCZ}$ & AMB & TEL & $\mathrm{HCZ}$ & AMB & TEL & $\mathrm{HCZ}$ & AMB & TEL \\
\hline 12.5 & 5 & 40 & 12.48 & 4.99 & 40.05 & 99.84 & 99.8 & 100.12 \\
\hline
\end{tabular}

Table 4: Intraday precision of the method

\begin{tabular}{lccc}
\hline Parameters & Hydrochlorothiazide & AmlodipineBesylate & Telmisartan \\
\hline Peak areas & 10250563 & 14552309 & 11608817 \\
& 10236221 & 14428385 & 11780467 \\
& 10253177 & 14530297 & 11791373 \\
Mean & 10246654 & 14503664 & 11726886 \\
SD & 9129.000457 & 66115.73396 & 102395.7653 \\
\%RSD & 0.08 & 0.45 & 0.87 \\
\hline
\end{tabular}


peaks were obtained for HCT, AMB and TEL at the retention times $2.53 \mathrm{~min}, 3.83 \mathrm{~min}$ and $7.10 \mathrm{~min}$, respectively. The optimized chromatogram for $\mathrm{HCT}$, AMB and TEL $\left(20 \mu \mathrm{g} \mathrm{mL}^{-1}\right)$ were shown in Figure 3. The resolution (RS) between $\mathrm{HCT}$ and $\mathrm{AMB}$ are 1.35; AMB and VAL are 2.25.

\section{Method validation}

The developed method was validated as per $\mathrm{ICH}$ guide lines. The system suitability parameters like capacity factor, number of theoretical plates, and USP tailing factor for all the analytes were found to be within the limit indicating the suitability of the system (Table 1). The number of theoretical plates and the USP tailing factor were within the acceptance criteria of $>2000$ and $\leq 1.5$, respectively, indicating good column efficiency and optimum mobile phase composition.

\section{Linearity}

Linearity was tested in the concentration range 20-100 $\mu \mathrm{g} \mathrm{mL}^{-1}$ for HCT, AMB and TEL. The solutions were chromatographed six times, in accordance with the International Conference on Harmonization. Separate calibration plots for HCT, AMB and TEL were constructed by plotting peak area against the respective concentrations and the method was evaluated by determination of the correlation coefficient and intercept, calculated in the corresponding statistical study (ANOVA; P < 0.05 ), correlation coefficient $r^{2}$ values $>0.999$ and intercepts very close to zero confirmed the good linearity of the method. The $P$ values calculated for the calibration plots were greater than 0.05 , indicating the variances were not significantly different (Table 2).

\section{Precision}

The precision of the method was determined by repeatability and intermediate precision studies. Intraday and Inter day precision was determined by repeating assay three times on same day for intraday (Table 4) and on three different days for inter day precision (Table 5). The intraday precision ranges from 0.08 to $0.12,0.45$ to 0.75 and 1.03 to 1.70 for $\mathrm{HCT}, \mathrm{AMB}$ and TEL,

Table 5: Intraday precision of the method

\begin{tabular}{lccc}
\hline Parameters & Hydrochlorothiazide & AmlodipineBesylate & Telmisartan \\
\hline Peak areas & 10285752 & 14355863 & 11744526 \\
& 10240563 & 14538886 & 11714579 \\
& 10218836 & 14272729 & 11791373 \\
Mean & 10248384 & 14389159 & 11750159 \\
SD & 34136.635 & 136166070 & 38705.69 \\
\%RSD & 0.33 & 0.94 & 0.32 \\
\hline
\end{tabular}

Table 6: results of recovery analysis

\begin{tabular}{lcccc}
\hline Drug & Amount taken $\left(\mu \mathrm{g} \mathrm{mL}^{-1}\right)$ & Amount added $\left(\mu \mathrm{g} \mathrm{mL}^{-1}\right)$ & Recovery (\%) & S.D \\
\hline HCT & 50 & 10 & 99.22 & 0.6493 \\
& 50 & 30 & 98.90 & \\
\multirow{2}{*}{ AMB } & 50 & 50 & 100.15 & \\
& 50 & 10 & 102.20 & 1.1405 \\
& 50 & 30 & 100.25 & \\
TEL & 50 & 50 & 100.20 & \\
& 50 & 10 & 102.22 & 0.7791 \\
& 50 & 30 & 101.08 & \\
\hline
\end{tabular}


<smiles>CCOC(=O)C1=C(COCCN)NC(C)=C(C(=O)OO)C1c1ccccc1Cl</smiles>

Hydrochlorothiazide

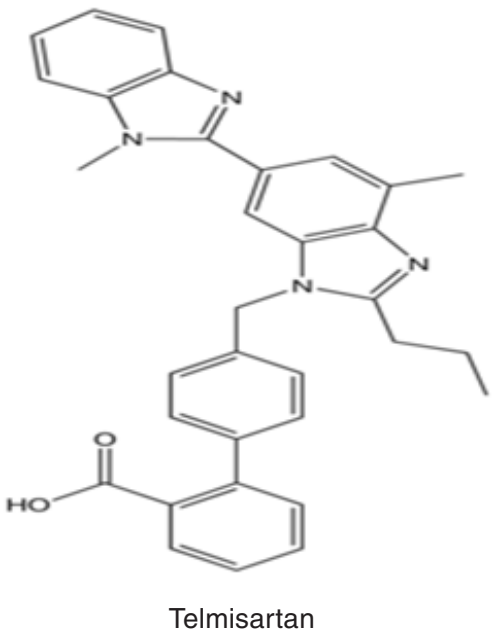

Fig. 1: Chemical structures of Hydrochlorothiazide, Amlodipine Besylate and Telmisartan

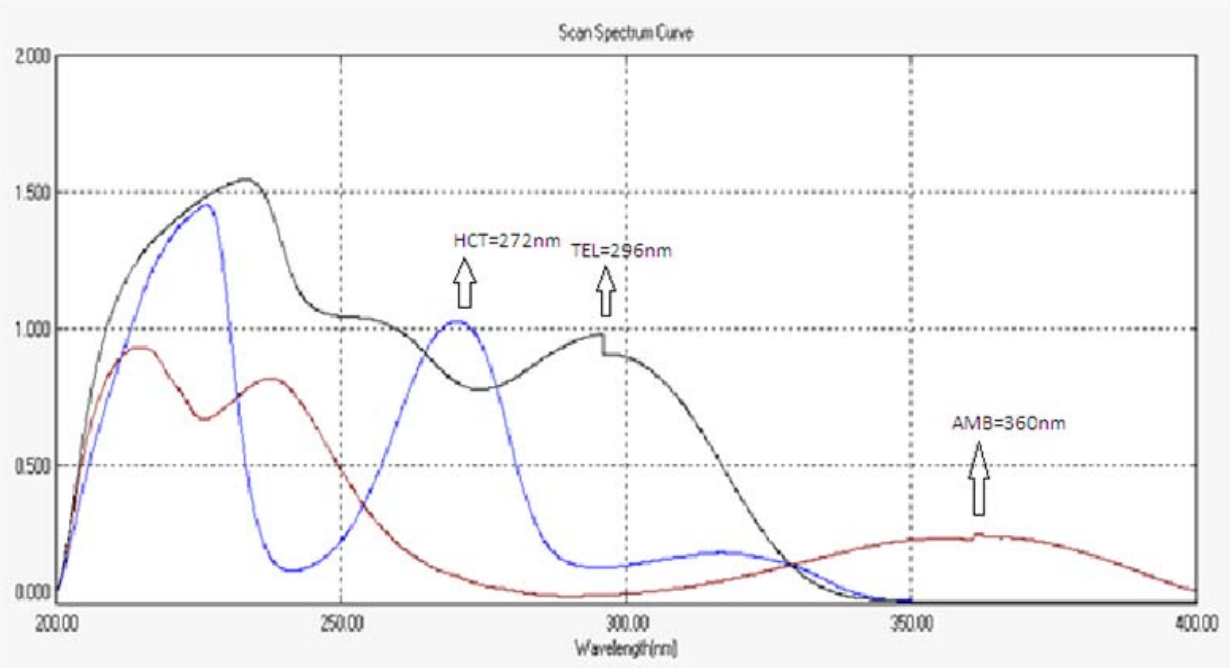

Fig. 2: Overlain UV spectra of HCT, AMB and TEL

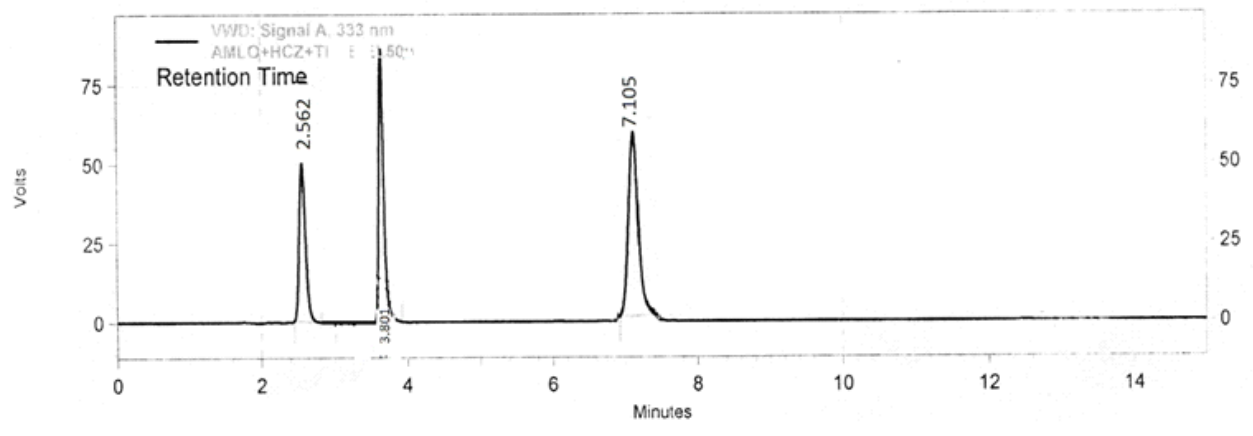

Fig. 3: Optimized chromatogram for HCT, AMB and TEL 


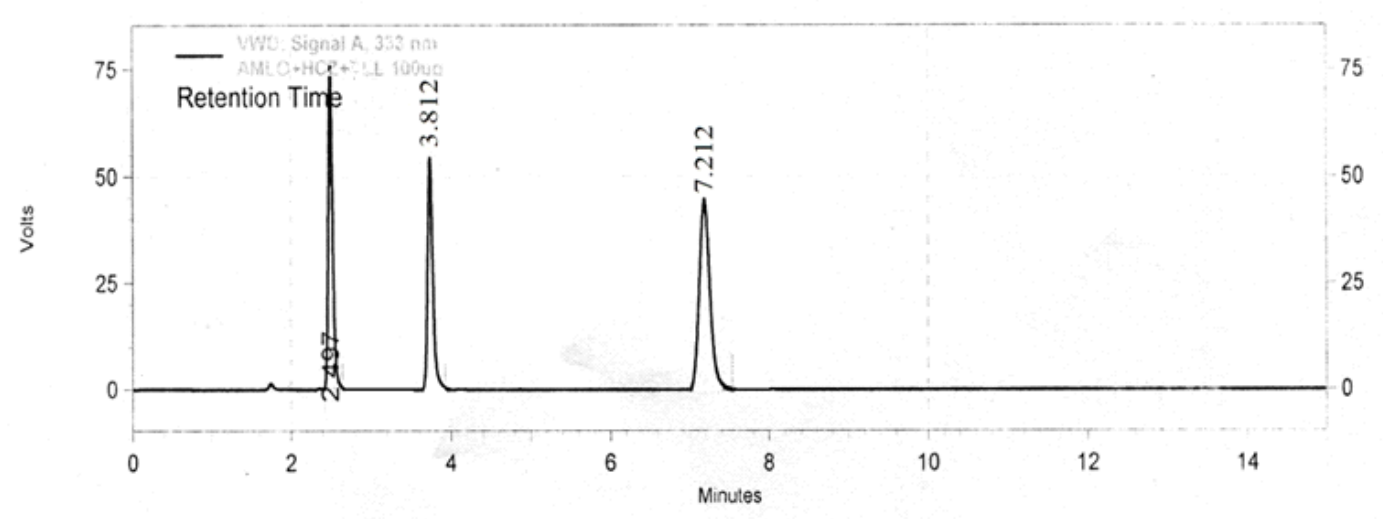

Fig. 4: Chromatogram for HCT, AMB and TEL

respectively. The inter day precision ranges from 0.33 to $0.79,0.94$ to 1.07 and 0.32 to 0.58 for $\mathrm{HCT}$, $\mathrm{AMB}$ and $\mathrm{TEL}$, respectively.

\section{Accuracy}

To ensure the reliability and accuracy of the method, the recovery studies were carried out by adding a known quantity of drug with pre analyzed sample and contents were reanalyzed by the proposed method. To check the accuracy of the developed methods and to study the interference of formulation excipients, analytical recovery experiments were carried out as per $\mathrm{ICH}$ guidelines. The results of the recovery studies and its statistical validation data were given in table 6 which indicates high accuracy of the proposed method. The percentage recovery was found to be in the range of $100.15 \%$ for $\mathrm{HCT}, 100.20 \%$ for $\mathrm{AMB}$ and $100.73 \%$ for TEL.

\section{Robustness}

As defined by the $\mathrm{ICH}$, the robustness of an analytical procedure describes to its capability to remain unaffected by small and deliberate variations in method parameters. Robustness was performed by small variation in the chromatographic conditions and found to be unaffected by small variations like $\pm 2 \%$ variation in volume of mobile phase composition, $\pm 0.1 \mathrm{~mL}$ $\mathrm{min}^{-1}$ in flow rate of mobile phase, \pm 0.1 variation in $\mathrm{pH}$.

\section{Specificity}

The specificity of the HPLC method was ascertained by analyzing standard drug and sample solutions. The retention time of HCT, AMB and TEL was confirmed by comparing the retention time with that of the standard.

\section{Assay of Tablet Formulation}

The assay of commercial tablets was established with present chromatographic condition developed and it was found to be more accurate and reliable. The percentage label claim present in tablet formulation TELVAS ${ }^{*}$-3D was found to be 99.84, 99.8, 100.12 for HCT, AMB and TEL, respectively. The chromatogram for the analysis of formulation is shown in figure 3 , Precision of the method was confirmed by the repeated analysis of formulation for six times (Table 3).

\section{Stability}

The assay of the three drugs was unaffected in different conditions indicating the stability indicating capability of the method. The chromatogram of the three drugs stored after 48 hrs at $70^{\circ} \mathrm{C}$ was shown in figure 4 .

\section{CONCLUSIONS}

A simple isocratic RP - HPLC method with UV detection has been developed for simultaneous determination of HCT, AMB and TEL. The method was validated for accuracy, precision, specificity, and linearity. The run time is relatively short (15 min), which enables rapid quantification of many samples in routine and quality control analysis of tablets. Thus the proposed method is rapid, 
selective, requires a simple sample preparation procedure, Moreover, the lower solvent consumption leads to a cost effective and represents a good procedure of HCT, AMB and TEL determination in bulk and in pharmaceutical dosage forms.

\section{ACKNOWLEDGEMENTS}

The authors are thankful to the Mylan Labs limited, Hyderabad for providing gift sample of Telmisartan, amlodipine besylateand hydrochlorothiazide and also to the management of Chebrolu Hanumaiah Institute of Pharmaceutical Sciences, Chowdavaram, Guntur for providing facilities and great support to carry out the research work.

\section{REFERENCES}

1. S.Budavari, The Merck Index. $14^{\text {th }}$ Edn., Whitehouse Station, NJ: Merck Research Lab, Division of Merck? Co. Inc., USA, 2006; 827

2. M.M. Baing, V.V.Vaidya, R.T.Sane, S.N.Menon and K.Dalvi. Chromatographia, 2006, 64(5), 293 - 296.

3. K.P.Bhusari, P.B.Khedekar, Seema Dhole and V.S.Banode. Indian J Pharm Sci, 2009, 71(5), 505 - 508.

4. S.L.Daniels and A.J.Vanderwielen. J Pharm Sci, 1981, 70 (2), 211 -215.

5. D.Tian, X.Tian, T.Tian, Z.Wang and F.Mo. Indian J Pharm Sci, 2008, 70 (3), 372 - 374.

6. H.Taomin, H.Zhong, Y.Bei, S.Luping, Z.Xiaowei and D.Gengli. J Pharm Biomed Anal, 41 (2), 644 -648 (2006).

7. B.Neela Manish, D.Snehal Jawaharlal, M.Harinath Nivrutti and C.Prafulla Balkrishna. Asian J Res Chem, 2 (4), 393 - 397 (2009).

8. S.Pallavie, G.Deepali, K.Rupali, D. Pandurang and B.Kishor. Asian J Res Chem, 2009, 2(4), 553 - 555.

9. G.D.Vaijanath, B.S.Sweta, P.K.Pravin, P.Manisha and K.J.Vivek. J Pharm Biomed Anal, 2008, 46 (3), 583 -586.

10. K.llango, P.B.Kumar and V.R.V.Prasad. Indian J Pharm Sci, 1997, 59(6), 171 - 173.

11. Y.Feng, L.Zhang, Z.Shen, F.Pan and Z.Zhang. J Chromatogr Sci, 2002, 40(1), 49 - 53.

12. J.Bhatt, S.Singh, G.Subbaiah, B.Shah, S.Kambli and S.Ameta. J Biomed
Chromatogr 2007, 21, 169 - 175.

13. Reddy, G.S., Reddy, S.L.N.P., Reddy, L.S., Orient J. Chem., 2013, 29(4), 1371-1380.

14. Indian Pharmacopoeia, Controller of Publication, Govt. of India, Ministry of Health and Family Welfare, New Delhi, 2010; 2: 714, 318.

15. British Pharmacopoeia, Vol. 1, London: Her Majesty's Stationary Office; 2009, 2008, 565.

16. P.Ajith, H.Sawarkar, Mukesh Singh, P.Kashyap, G.Priyanka. International Journal of Chem. Tech Research, 2011, 3, 657-660.

17. G.Rekha, K.Sunil and P.Sharma. Journal of applied pharmaceutical sciences, 2011, 1, 46-49.

18. C.H.Phani Kishore, V.Bhanu Prakash Reddy, M.K.Dhanashri. Int J Res Pharm Sci, 2010; 1, 493-501.

19. R.Patel Amit, K.Chandrul Kaushal. International Journal of Pharmaceutical and Biomedical Research, 2011, 2, 4-16.

20. $\mathrm{ICH}$ Q2A; Guidelines on validation of analytical procedure; Definitions and terminology, Federal Register, 1995, 60, 11260.

21. $\mathrm{ICH}$ Q2B; Guidelines on validation of analytical procedure; Methodology, Federal Register, 1996, 60, 27464.

$22 \mathrm{ICH}$ harmonized tripartite guideline, stability testing of new drug substances and products, Q1A (R2) , 2003, 1, 15. 